ART. XXV.-Notice of some Fossil Birds, from the Cretaceous and Tertiary Formations of the United States; by O. C. Marsh, Professor of Paleontology in Yale College.

The remains of Birds described from European rocks are at present limited in the Mesozoic to the famous Archooopteryx of the Jurassic, and apparently a single species only from the Cretaceous; but in the Tertiary period, and especially in the Miocene and Pliocene, this class was very fully represented by many of the modern types, and numerous species have already been clescribed by Owen, von Meyer, Gervais, Hébert, Lartet, Gaudry, A. Milne-Edwards, and other paleontologists. In this country, however, since the discovery that the three-toed footprints in the Connecticut river sandstone were probably all made by Dinosaurian reptiles, no species of birds have been included in our extinct fauna, as, with this apparent exception, none have been described from any North American strata. Recent explorations, however, have shown that remains of this class are not wanting in the later formations of the United States, and that the Cretaceous and Tertiary, especially, contain representatives of many interesting forms.

The bones of birds, as might naturally be expected, are usually the rarest of vertebrate fossils, particularly in marine deposits ; but, fortunately, those parts of the skeleton most likely to be preserved are especially characteristic, so that even small portions not unfrequently admit of accurate determination, although their investigation is a work of considerable difficulty, even where ample material for comparison with recent species is available. The specimens briefly described in the present preliminary notice, although nearly all fragmentary, are in an excellent state of preservation; and most of them show strongly marked characters, which indicate at least the near affinities of the species they represent. If the interpretation of them here given be correct, they prove the existence, in this country, even before the close of the Mesozoic, of an interesting and varied group of aquatic birds, and suggest for this period a very rich avine fauna. 


\section{Remains of Cretaceous Birds.}

Among the fossils under consideration are specimens indicating five species of Cretaceous birds, the remains of which were found in the greensand of New Jersey, and with a single exception in the middle marl bed. The specimens are all mineralized, and in the same state of preservation as the bones of the extinct reptiles which occur with them in these deposits; and hence are readily distinguished from the remains of Post-tertiary and recent birds, which have occasionally been found near the surface in the greensand excavations of that region. In most instances, moreover, a record of the discovery places the geological horizon of the present fossils beyond a doubt.

\section{Laornis Edvardsianus Marsh, gen. et sp. nov.}

The most interesting, in many respects, of the specimens from the Cretaceous is a portion of the shaft and distal extremity of a left tibia, which indicates a species, apparently of a swimming bird, nearly as large as the common wild swan (Cygnus Americanus Sharpless). The specimen is well preserved, and shows that the tibia, when entire, was of medium length, and quite robust. The condyles of the distal end are broader anteriorily than deep, the inner condyle being more prominent in front, and the outer one projecting somewhat farther behind. The inter-condyloid space is wider than either condyle. The supratendinal bridge-one of the most characteristic portions of the skeleton, when present-is well ossified, and still uninjured. It is submedial in position, straight, transverse, of moderate width, and spans a deep and well defined canal, which was traversed by the extensor tendon of the toes. The outer margin of the canal is low and obtuse, as in most of the Gallinaceous birds. The inner margin is the more prominent, and just above the upper edge of the bridge it supports an elongated tubercle for the inner attachment of the oblique ligament. Opposite the bridge, on the other margin, there is a large triangular elevation, which is separated by a shallow transverse groove from the exterior condyle. To this prominence the outer end of the oblique ligament was attached. The outlet of the canal above the bridge is transversely elliptical in outline, and the one below more oval, and looking forward, and slightly outward. Just below this aperture, there is a shallow depression in the inter-condyloid space, similar in shape and position to that in the tibia of the wild goose (Bernicla Canadensis Boie), although rather deeper, and more oblique. The under trochlear surface is but slightly concave transversely, and has a faint median elevation, as in the tibia of the swan; but in the present specimen this is continued along the entire posterior surface, which is broad, with a slight, transverse concavity. On the lower surface 
of the inner condylar ridge there is a shallow notch, resembling in shape and position that in the tibia of some of the Gulls, especially the Herring Gull (Larus argentatus Brünn.). The ectocondyloid surface is unusually circular in outline, and has, for the attachment of the external, articular ligament, a low tubercle, a little behind and below its central point. Just in front of this, there is a shallow groove extending directly upward. The ento-condyloid surface is moderately transverse, and has on its anterior portion, for the attachment of the internal ligament, a large irregular tubercle, which is connected by a low ridge with the prominent inner margin of the tendinal canal. A portion of the fibular ridge remains on the upper part of the specimen, and a faint indication of its continuation can be traced nearly to the ecto-condyloid surface, where it passes into a small, acute, elongated tubercle, which is just outside of the triangular prominence, already mentioned. Between these two elevations, there is a deep groove for the tendon of the short tibial muscle, and in its inner margin a small elongated foramen, leading obliquely downward and inward.

The portion of the shaft preserved is robust, and somewhat flattened in an antero-posterior direction. In the lower fourth of the bone, the transverse diameter gradually increases, and reaches its maximum at the extremity of the distal condyles. The shaft curves forward slightly just where it begins to expand above the lower condyles, closely resembling in this respect the tibia of the turkey; and it has at this point little of the marked inward curvature, characteristic of the swimming birds, but is so straight, that its median plane, if continued, would divide the trochlear surface nearly equally.

The dimensions of the specimen are as follows :-

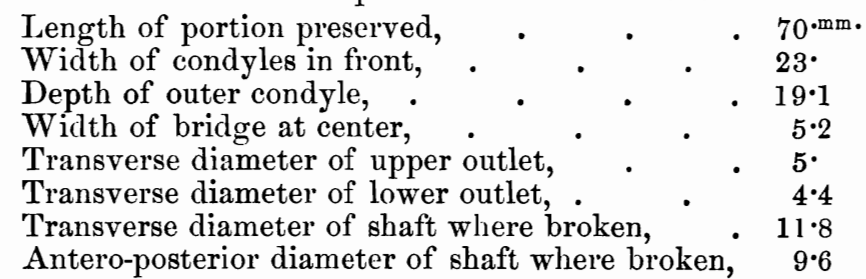

A consideration of the characteristic points of this interesting fossil leads to the conclusion that it should be placed in the order Natatores, but additional remains will probably be required to determine its exact affinities. It shows a strong resemblance in several respects to the Lamellirostres, and also to the Longipennes, but differs essentially from the typical forms of both these groups. For the extinct genus evidently represented by this specimen the name Laornis* is proposed. The

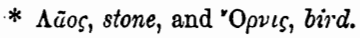


species may very justly be named Laornis Edvardsianus, in honor of M. Alphonse Milne-Edwards, of Paris, whose great work on Fossil Birds, now in course of publication, promises to place this hitherto neglected branch of paleontology on a firm foundation.*

This unique specimen was found in the greensand of the upper, Cretaceous marl bed, at Birmingham, New Jersey, in the pits of the Pemberton Marl Company, and was presented to the Museum of Yale College by the superintendent, J. C. Gaskill, Esq.

Palceotringa littoralis Marsh, gen. et sp. nov.

The present collection contains, also, some remains of wading birds from the Cretaceous, and among them are specimens indicating two species, apparently belonging to the Gralloe. Each of these is represented by a portion of the shaft, and the lower extremity of a left tibia, and probably by some other fragmentary, but less characteristic parts of the skeleton. The tibia of the larger species resembles in size and general form that of the European Curlew (Numenius arquata Linn.). The condyles of the distal end are expanded anteriorly, but in their posterior extension continue upward as acute, prominent ridges. The inner condyle is somewhat narrower than the outer. The intercondyloid space is smooth, with the exception of a faint transverse groove, and is wider than either condyle. The trochlear surface is broad, slightly concave transversely, and its median portion nearly flat, especially at the extremity. Its upper, posterior surface projects slightly beyond the face of the adjoining shaft. The ecto-condyloid surface is smooth, and somewhat concave. The supratendinal bridge is narrow, very thin, transverse, and has its outer edge on the median line. The tendinal canal is very broad and deep, and its floor nearly flat. In its general features it resembles the canal of the Herring, or Silvery Gull. The aperture below the bridge is oval in outline, and looks forward, and slightly inward and downward. On the outer margin of the canal, just above the exterior condyle, there is a triangular rugose surface, to which the oblique ligament was apparently attached. This surface projects outward, so as to produce a slight swelling at this point on the side of the shaft. The interior margin of the canal is the more acute, and just above the bridge has on its inner edge a small elongated and inflected tubercle for the attachment of the upper end of the oblique ligament.

The shaft of the tibia is slender, and has its narrowest part at the beginning of the lowest fourth, or a little above where the margins of the tendinal canal begin. From this point

* Recherches sur les Oiseaux Fossiles de la France. 4to. Paris, 1867-70. 
downward, the shaft curves slightly forward, and also expands transversely, but much more gradually than in most wading birds. The lower half of the tibia is unusually flat in front, and very convex behind. A transverse section of the broken end is broadly oval.

The admeasurements of this tibia are as follows:-

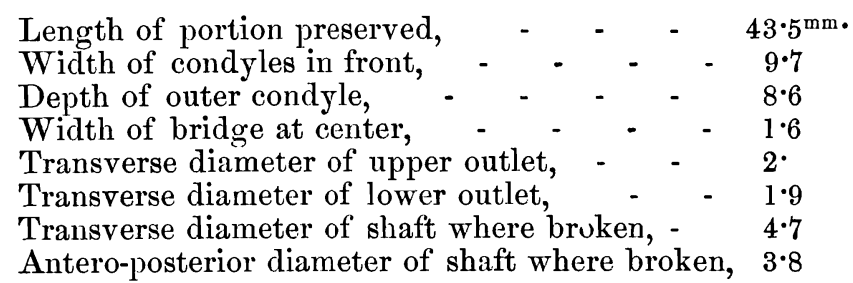

The remains on which this species is established are from the Cretaceous greensand of the middle marl bed. They were discovered by Nicholas Waln, Esq., in his marl pits, at Hornerstown, New Jersey, and by him presented to the Museum of Yale College.

Palceotringa vetus Marsh, sp. nov.

The present species is indicated by the lower portion of a right tibia, which is of peculiar interest, as it apparently was the first fossil bird-bone discovered in this country. It is mentioned by Dr. Morton in his Synopsis, as "the tibia of a bird belonging to the genus Scolopax;"* and subsequently by Dr. Harlan, who regarded it as the femur of a bird allied to the same genus. $\dagger$ The specimen has since remained in the collection of the Academy of Natural Sciences in Philadelphia, but no description of it has been published, probably owing to the fact that it has generally been regarded as a recent species, accidentally introduced into the deposit where found. It is, however, thoroughly fossilized, and in precisely the same state of preservation as the remains of birds, since discovered in the same region, which are known to be of Cretaceous age, and hence its antiquity cannot now be fairly called in question.

This specimen indicates a species about half the size of $P$. littoralis, or about as large as the Hudsonian Godwit (Limosa Hudsonica Swain.). In general form and proportions it closely resembles the tibia just described. This is especially evident in the very gradual, transverse expansion of the lower end of the tibia; and in the broad concave trochlear surface, with no indications of a median elevation, or of the peculiar flattening of the inferior surface, which is seen in many of the Snipe family.

* Synopsis of the Organic Remains of the Cretaceous of the U. S., p. 32, Philadelphia, 1834.

+ Medical and Physical Researches, p. 280, Philadelphia, 1835.

Am. Jour. Sci.-Second Series, Vol. XlIX, No. 146.-March, 1870. 
One of the most important differences between them, however, is in the supra-tendinal bridge, which in the present specimen is broader and stouter, and the outlet below looks more directly forward. The inter-condyloid space, also, has a distinct transverse depression, which is but faintly indicated in the former specimen. The rugose surface on the outer margin of the canal is here replaced by three tubercles, the largest of these, to which the oblique ligament was doubtless attached, being nearly opposite the bridge, and the other two above and outside of it. The anterior face of the tibia above the bridge is nearly flat, with a faint median rising, which throws the true tendinal canal against its inner margin. In the previous specimen this elevation does not exist, the corresponding space being transversely concave. The ecto-condyloid surface in this species is almost flat, with a slight elevation just below its central point. The ento-condyloid face is quite concave posteriorly, but near the middle of its anterior projection has a very small tubercle for the attachment of the lateral, articular ligament.

The principal dimensions of this tibia are as follows:-

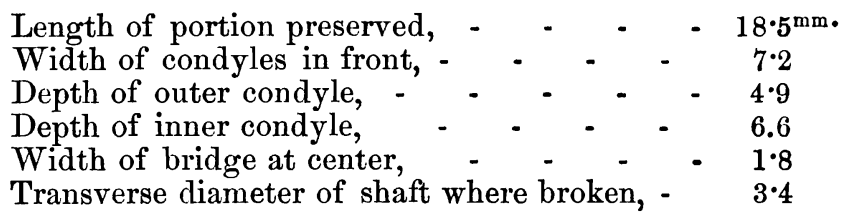

The differences noted above between this specimen and the tibia of $P$. littoralis render it probable that additional remains would show that they belong to distinct genera; but for the present they may very properly be placed together in the genus Palceotringa, and the present species be named Palceotringa vetus. The specimen, according to the authorities already cited, was found in the marl at Arneytown, New Jersey, which would imply that it was from the lowest, Cretaceous marl bed.

Telmatornis priscus Marsh, gen. et sp. nov.

The most important of the remains on which this species is founded is the lower half of a left humerus. The specimen is in perfect preservation, and, fortunately, a very characteristic part of the skeleton. In general appearance it resembles the humerus of some of the Rail family, and the species it represents is probably related to this group of birds. Evidence of this is seen in the unusual flattening of the lower part of the shaft and distal extremity; in the small articular condyles; in the diminutive protuberance for the attachment of the extensor muscle of the hand; and in the oval impression of the anterior brachial muscle. The latter has, however, in this

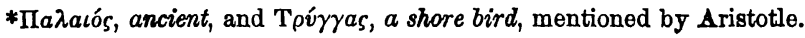


specimen a more oblique position than in most of the Rallidoe. It resembles the corresponding impression in the woodcock, (Philohela minor Gray), but is situated higher up, and its superior margin is less distinctly defined. The distal end of this humerus resembles in its main features that of the Green Heron (Butorides virescens Bonap.), but differs widely from it in being much more compressed, and in having the imprint of the anterior brachial muscle much shorter, and more oblique.

The most important dimensions of this humerus are as follows:

$\begin{array}{ll}\text { Length of specimen preserved, } & 25 \cdot \mathrm{mm} \cdot \\ \text { Vertical diameter of distal end, } & 11 \cdot 2 \\ \text { Transverse diameter through radial condyle, } & 5 \cdot 6 \\ \text { Depth of shaft where broken, - - } & 4 \cdot 4 \\ \text { Transverse diameter of shaft where broken, - } & 3 \cdot 6 \\ \text { Length of impression of anterior brachial muscle, } & 5 \cdot 8\end{array}$

These remains apparently indicate a genus of birds distinct from any yet described, for which the name Telmatornis* is proposed. The present species, which was about the size of the King Rail (Rallus elegans Aud.), may be called Telmatornis priscus. The remains of the species at present known were found in the Cretaceous greensand of the middle marl bed, in pits of the Cream Ridge Marl Company, near Hornerstown, New Jersey, and were presented to the Museum of Yale College by John G. Meirs, Esq.

Telmatornis affinis Marsh, sp. nov.

This species is also based, essentially, on the lower portion of a right humerus, which was found at the same locality, and in the same stratum as the one just described. It closely resembles that specimen in most important particulars, but a careful comparison shows some points of difference which appear to justify its separation. The most apparent of these are the following :The notch between the radial and ulnar condyles is somewhat deeper; the elongated tubercle, on the inner surface behind the notch, which confines the upper tendon of the triceps muscle, is larger; the impression of the anterior brachial muscle on the outer surface is higher up, and more shallow; and the epitrochlear elevation is more prominent. The specimen indicates, moreover, a species considerably smaller than the one mentioned above. Its principal measurements are as follows:-

\begin{tabular}{l} 
Length of portion preserved, \\
Vertical diameter of distal end, - - - $\quad-12^{\cdot \mathrm{mm}}$. \\
\hline
\end{tabular}

Transverse diameter through radial condyle, - $4 \cdot 8$

Vertical diameter of shaft where broken, - $\quad 5 \cdot 6$

Length of impression of anterior brachial muscle, $\quad 5 \cdot 8$ 
These remains, also, were found by John G. Meirs, Esq., near Hornerstown, New Jersey, and by him presented to Yale College, in behalf of the Cream Ridge Marl Company.

\section{Remains of Tertiary Birds.}

The few remains of birds hitherto discovered in the Tertiary deposits of the United States naturally show a much closer resemblance to recent species than those from the Cretaceous. In the specimens examined by the writer during the present investigation, which include, it is believed, all the remains of importance known from the formation in this country, no characters implying genera distinct from existing birds are apparent, and some of the fossils seem to indicate species nearly related to those now living. Future discoveries, however, will doubtless disclose more important differences between faunæ so remote in time.

\section{Puffinus Conradi Marsh, sp. nov.}

The collection of the Academy of Natural Sciences in Philadelphia has for many years contained the distal half of a left humerus, and the lower portion of a right ulna, of an aquatic bird, which were discovered in the Miocene of Maryland by 'T. A. Conrad, Esq. A brief mention of these specimens, and of some other ornithic remains from the United States, has already been made by Professor Leidy,* but no description of them has yet been published. The specimens are so well preserved, and so characteristic, especially the humerus, that the affinities of the species they indicate can be determined with tolerable certainty. The most marked feature of the humerus is the transverse obliquity of its shaft and distal extremity. Both are much compressed, and so turned that the common plane of their longer diameters, instead of being nearly vertical, as in the brachium of most birds, is here highly inclined inward and downward. Among the other characters of importance may be mentioned, the unusually small size of the ulnar condyle, the very deep, oval impression for the attachment of the anterior brachial muscle, and the presence of an elongated, compressed apophysis, extending outward and upward from the exterior margin of the distal end, just in front of the radial condyle.

This humerus has the following dimensions:-

$\begin{array}{lr}\text { Length of portion preserved, - } & -49 \cdot \mathrm{mm} \text {. } \\ \text { Vertical diameter of distal extremity, } & 13 \cdot 2 \\ \text { Transverse diameter of radial condyle, - } & 8 \cdot 6 \\ \text { Transverse diameter of ulnar condyle, } & 3 \cdot 8 \\ \text { Length of impression of anterior brachial muscle, } 5 \cdot 6 \\ \text { Breadth of impression of anterior brachial muscle, } 3 \cdot 8 \\ \text { Longer diameter of shaft where broken, - } & 7 \cdot 4 \\ \text { Shorter diameter of shaft where broken, - } & -5 \cdot\end{array}$

* Proceedings Acad. Nat. Sciences, Philadelphia, 1866, p. 237. 
A comparison of the present fossils with the corresponding parts of recent birds readily snows that the nearest allies of this extinct species must be sought in the Auk family, or among the Petrels ; as it is only in these groups of birds, that the peculiar obliquity of the humerus, noticed above, exists. In the Alcidoe, however, this oblique compression is greater than in the present specimen. The latter has, moreover, on its outer edge above the radial condyle, the long, pointed projection, which is not seen in the Auks, although present in the Petrels, Gulls, and some of the wading birds. The difference in size between the ulnar and radial condyles, and the remarkably deep, oval, impression for the attachment of the anterior brachial muscle show unmistakably that this humerus belongs to one of the Shearwaters, and apparently should be placed in the genus Puffinus, with which it corresponds in all essential particulars. In size and general features it apparently resembles most nearly the brachium of the Cinereous Petrel (Puffinus cinereus Gmelin, sp.), of the Pacific coast, but there are some points of difference between them which clearly imply that the species are distinct. The flat apophysis on the outer edge of the distal extremity is in the fossil specimen more pointed; the impression, on the lower surface, of the anterior brachial muscle is deeper, and its outline more sharply defined, which is also the case with the small epicondylar depressions for the attachment of the muscles of the forearm. The bone indicates, moreover, a somewhat smaller bird.

The distal half of the right ulna, which was found with the humerus, apparently belonged to a bird of the same species, although its size would seem to indicate that it pertained to a smaller individual. The species represented by these remains may appropriately be named for its discoverer, T. A. Conrad, Esq., who has been so long and honorably identified with American paleontology.

\section{Catarractes antiquus Marsh, sp. nov.}

Among the other bird remains in the Museum of the Philadelphia Academy, is a very perfect left humerus, from Tarborough, Edgecombe county, North Carolina, which was presented by Dr. Booth. The geological position of the specimen is not definitely known, but its state of preservation and mineralization render it extremely probable, at least, that it is from the Tertiary deposits of that region. This humerus shows the same transverse obliquity which characterized the specimen just described, and so strongly resembles in other respects also the same bone in the Auks, that it should evidently be referred to that family. It approaches most nearly the humerus of the Guillemots, especially those now included in the genus Catar- 
ractes, with which it appears to coincide in all important characters.

The principal dimensions of this humerus are as follows:

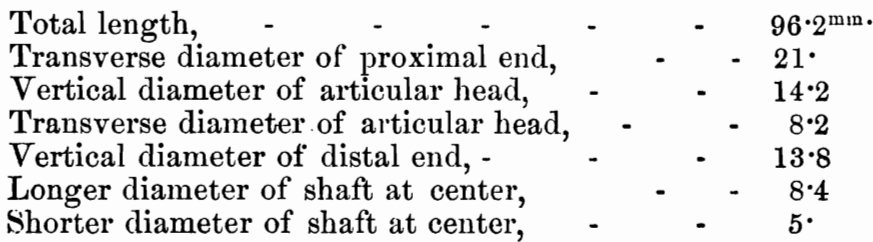

The present specimen shows so many points of resemblance to the humerus of the Thicked-billed Guillemot (Catarractes lomvia Linn.), that it will probably find in this species its nearest living representative. It indicates, however, a somewhat larger bird; and on carefully comparing the humeri of the two, some marked differences may be detected, which are quite sufficient to prove the species distinct. The most important of these are the following:- The head of the humerus in the fossil specimen is more obtusely rounded, both transversely and vertically; the two grooves, on the inner surface of the distal extremity, for the tendons of the triceps muscle, are of nearly equal width, the upper depression being somewhat wider than the other, but in C. lomvia Linn. the lower groove is much the broader; the ulnar condyle has, moreover, on its interior surface, a small obtuse tubercle, extending upward and inward, as in the humerus of the Great Auk (Alca impennis Linn.), while this projection is wanting in the Thicked-billed Guillemot; the lower face of the same condyle also differs from that of the latter species in forming a much narrower crescent; and in several minor points of structure a similar want of correspondence may be seen.

A right humerus, closely resembling the preceding specimen, and evidently belonging to the same genus, was presented to the Philadelphia Academy a few years since by Dr. A. C. Hamlin, who obtained it in the Post-tertiary clays, near Banyor, Maine, at a depth of forty-seven feet below the surface. It appears to be distinct from the above species, as well as from C. lomvia Linn., and will be described at an early day by the writer, in a paper now in course of preparation on the remains of some Quaternary birds.

Grus Haydeni Marsh, sp. nov.

The various explorations that have been made in the Tertiary deposits of the Upper Missouri region, so remarkably rich in mammalian remains, have, strange to say, brought to light but a single fragmentary specimen which can with certainty be referred to the class of birds; although the material collected 
there has been carefully examined for these fossils by several paleontologists. The only specimen hitherto detected was obtained by Dr. F. V. Hayden, several years since, in the later Tertiary beds of the Niobrari river. It is the distal extremity of a left tibia, one of the most common, and most characteristic parts of fossil birds, and indicates unmistakably a large species of the genus Grus, or Cranes. Although the specimen is somewhat injured, the most important parts are well preserved, and appear to exhibit good distinctive characters. The inner articular condyle is partially broken away, but was evidently much narrower than the other, and is continued far backward as a very sharp ridge. The outer condyle is somewhat flattened below, and its posterior extension projects beyond the surface of the shaft, although not so far as that of the inner condyle. The trochlear space is rather narrow, and has its deepest part inside of the median line. It is slightly concave transversely below, and deeply so posteriorly. The ecto-condyloid surface is concave, but has a low tubercle just in front of its central point. The supratendinal bridge is very broad, internal, transverse, and its surface is concave vertically. It spans a very narrow, but deep, internal canal. The lower outlet is subtriangular in outline, and looks obliquely forward and downward. The superior aperture is broadly oval, and the upper edge of the bridge is continued slightly above it on either side of the canal. The lower opening has its upper, straight margin slightly rounded, and its lower edge is formed by a sharp ridge, which separates it from the nearly flat intercondyloid space. External to this aperture is a prominent tubercle, which has its inner edge on the median line, and is connected above by a low ridge with the outer elongated tubercle for the attachment of the oblique ligament. A more prominent crest extends obliquely downward, and unites it with the external condyle. The inner margin of the canal is bounded by a well defined ridge, which, just above the bridge, is inflected over the edge. Externally, the margin of the canal is low, and indistinct. The groove for the tendon of the short tibial muscle is well defined, and bounded outwardly by a low ridge, which causes a projection on the exterior surface of the shaft.

The principal dimensions of this specimen are as follows:-

Length of portion preserved, - _ $\quad$ - $\quad 31 \cdot \mathrm{mm}$.

Depth of external condyle, $\quad-\quad$ - $\quad 19 \cdot 2$

Width of supratendinal bridge, - _ _ $\quad 7 \cdot 2$

Width of upper outlet, - _ _ _ $\quad 2 \cdot 4$

Width of lower outlet, - - _ $\quad$ - $\quad 3.6$

Transverse diameter of shaft where broken, - $\quad 12 \cdot 6$

Antero-posterior diameter of shaft where broken, $\quad 8 \cdot 2$

This specimen, also, belongs to the Academy of Natural 
Sciences in Philadelphia, and the extinct species it indicates is named for Dr. F. V. Hayden, whose explorations have added so much to our knowledge of the geology of the Upper Missouri, and Rocky Mountain regions.

\section{Graculus Idahensis Marsh, sp. nov.}

A collection of Tertiary fossils from Idaho, lately received by Professor Newberry, of Columbia College, contained the greater portion of the left metacarpal bone of an aquatic bird, which he has kindly loaned to the writer for examination. The specimen is in perfect preservation, and has such marked characters that it will evidently admit of at least approximate determination. Among the most prominent features of the fossil, at its proximal extremity, are, the great anterior projection of the radial apophysis, which is also elevated, and its superior portion considerably compressed ; the deep anterior carpal fossa, which extends into the base of the carpal articular surface; the very deep and narrow posterior carpal fossi, which is auriform in outline, and extends obliquely inward and forward; and the internal and oblique position of the smaller metacarpal bone. The pisiform tubercle on the inner surface is of medium size, and its summit nearly flat. A sharp ridge extends from its anterior edge directly upward to the margin of the articular surface. The groove in front of this tubercle is very deep and broad. The fossa for the attachment of the inner lateral ligament of the wrist is also deep, and has, apparently, a small pneumatic opening near its center. The smaller branch of the metacarpal bone was slender, and but little separated from the larger one. Its outer edge at its superior attachment is on the median line, and opposite to this point, on the outer posterior edge of the large metacarpal, there is a small tubercle, to which the superior flexor muscle of the hand was attached. The lower extremity of the specimen has, unfortunately, been lost.

The principal dimensions of this metacarpal bone are as follows :-

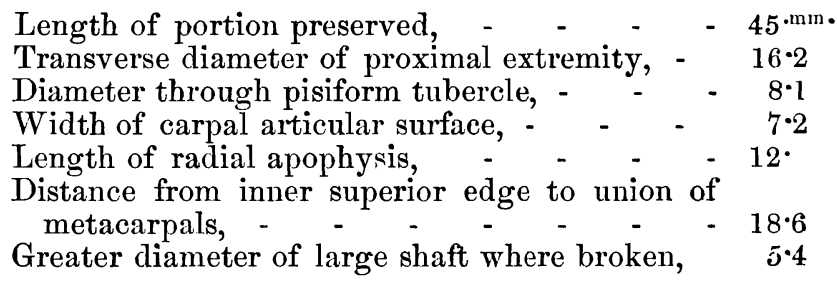

The species represented by this fossil appears to have been related to the Cormorants, and may be placed provisionally in the genus Graculus; the metacarpal of which the present speci- 
men resembles in nearly all important particulars. The most marked difference between them is the presence in the latter of the anterior carpal fossa. This interesting specimen, the only fossil bird bone yet found west of the Rocky Mountains, is from a fresh-water Tertiary deposit, probably of Pliocene age, on Castle Creek, Idaho Territory.

In addition to the acknowledgments made in the course of the present article, the writer desires, in conclusion, to express his grateful thanks to Professor Joseph Leidy, of Philadelphia, who generously placed in his hands for examination the various bird remains already mentioned as belonging to the Academy of Natural Sciences in that city. A more complete description, with illustrations, of all the remains here briefly noticed, and a determination of their nearer relations to living species, as well as the conclusions their discovery suggests, are reserved for a future communication.

Yale College, New Haven, Conn., Feb. 1st, 1870. 